\title{
Spatial Ability of Univerity Students in Mathematics Education
}

\author{
Isnaeni Umi Machromah \\ Mathematics Education Department \\ Muhammadiyah University of Surakarta \\ Surakarta, Indonesia. \\ isnaeniumi@ums.ac.id
}

\author{
Mega Eriska Rosaria Purnomo \\ Mathematics Education Department \\ Muhammadiyah University of Surakarta \\ Surakarta, Indonesia. \\ mega.eriska@ums.ac.id
}

\begin{abstract}
Spatial ability is a human qualification that is relevant to high degree to our lives. Spatial ability is one principal that influence to geometry skill for students. Thus, the aim of this research is identifying student's spatial ability particularly related to geometry skill. Kind of this research is qualitative description. Technique of collecting data is test of spatial ability. This research uses method-triangulation for validating data. Meanwhile, the steps for analyzing data are data reduction, data presentation, and conclusion. The result of this research showed about kinds of spatial ability that there is $69,69 \%$ student with imaginary manipulation of the solid, $24,39 \%$ students with representation of the projection, $65 \%$ students with reconstruction object, $60,6 \%$ students with objective cognitive map, and $46,06 \%$ students with balance cognitive map.
\end{abstract}

\section{Keywords-Geometry, Spatial Ability; Colleague}

\section{INTRODUCTION}

Geometry is one of main lecture which is given to students in Mathematics Education Department of Universitas Muhammadiyah Surakarta. There are so many kinds of Geometry's lecture such as Plane Geometry, Solid Geometry, Analytical Plane Geometry, Analytical Solid Geometry, and Non-Euclid Geometry. Besides, Geometry is one of subject that is though from elementary school until university. Thus, Geometry is one of important branch of knowledge in mathematics. Another point is that it is important for mathematics education students understand deeply about Geometry. The purpose of teaching geometry is not only develop students cognitive, but also it could form concrete thinking to abstract. Besides, geometry also helps students to analyze and interpret the problems, also it can be applied in other mathematics field by complete it with some tools [1]. Spatial ability is an important component of intellectual ability [2].

Another point is that geometry is one of the hard subject for students both in school or university as students should have the ability to visualize, describe images, draw shapes, and get to know shapes. Learning geometry is not only studies the definition but also analyzes the geometric properties of two dimensions and three dimensions, and also develops geometric relationships to determine location, apply transformation, use symmetry, visualization, spatial reasoning, and geometric modeling to solve problems [3]. In fact, there are many students in mathematics education department who have to study over again in the next year as they do not get the good scores and understand geometry well.
At academic year 2015/2016, there was $47,67 \%$ students from six class who got scores less than 63 on solid geometry lecture. It indicated that there were errors and difficulties which was done by students when solving problems on geometry. According to [4], student errors on solid geometry based on Newman theory consist of reading error, comprehension error, transformation error, process skill error, and encoding error. In addition, the dominant error from all types of error on solving solid geometry problems was related to visual spatial skill. Error at visual spatial skill was showed that students could not draw appropriate object based on problems, also intersection plane of solid object with plane, and students could not interpret what was the problems want, such as students did not draw correctly the point of extension line as they did not know how to draw extension line. Beside, students could not calculate the distance of two object as they could not imagine and analyze the object well. Another research [5] showed that errors in geometry are mostly made by students with low spatial intelligence because they have deficiencies in visual abilities. Thus, visual abilities are important aspect to learn geometry.

Spatial ability is generally thought to be related skill involving the retrieval, retention, and transformation of visual information in a spatial context and includes the ability to manipulate the information that represenred in visual [6]. Spatial ability is a human qualification that is relevant to high degree to our lives [7]. According to [7], components of spatial skill consist of five classification, they are (1) spatial perception which indentifying by the vertical and horizontal fixation of direction regardless of troublesome information; (2) spatial visualization is the ability of depicting of situations when the components are moving compare to each other; (3) mental orientation which identified by rotation of three dimensional solids mentally; (4) spatial relation is the ability of recognizing the relations between the parts of a solid; and (5) spatial orientation is the ability of entering into a given spatial situation. Based on [8], there are five important type of task to diagnose student's spatial ability in colleague. They are imaginary manipulation of the solid, the projection of solid, reconstruction, objective cognitive map, and balance cognitive map. At this research, the types of spatial ability use this classification.

Based on the explanation above, types of spatial ability and the error are needed to be analyze with reason and causative factor. Thus, the aim of this research is identifying student's spatial ability particularly related to geometry skill. 


\section{RESEARCH METHOD}

This research was qualitative research which describe profile of student's spatial ability in Geometry. Subject of this research were 6 students of $3^{\text {rd }}$ semester at Mathematics Education Department UMS. They had taken Geometry lecture. The six students consist of 2 students had high geometry skill, 2 students had medium geometry skill, and 2 students had low geometry skill. The source of data on this research were spatial ability test and interview with subjects. This research used time triangulation to fulfill the validity data. Besides, the technique of data analyze were collecting data, reduction, present data, and also conclusion.

\section{RESULT AND DISCUSION}

Based on spatial ability test, it was chosen a class with least average score, namely class of $3 \mathrm{~F}$. According to the test, there

\begin{tabular}{|c|c|c|c|c|c|}
\hline Subject & Number 1 & Number 2 & Number 3 & Number 4 & Number 5 \\
\hline SM-1 & True & $\begin{array}{l}\text { Subject could answer } 2 \text { part } \\
\text { correctly but the other one is } \\
\text { false. It is because He } \\
\text { imagined the object at wrong } \\
\text { direction. }\end{array}$ & True & $\begin{array}{l}\text { Subject just estimated the } \\
\text { distance of two objects and } \\
\text { did not compare with other } \\
\text { path. }\end{array}$ & True \\
\hline SM-2 & True & True & True & True & $\begin{array}{l}\text { Some answers were not } \\
\text { true as he did not calculate } \\
\text { appropriate so he could not } \\
\text { determine the real form of } \\
\text { object. But he could } \\
\text { analyze the distance } \\
\text { estimation well. }\end{array}$ \\
\hline SM-3 & True & $\begin{array}{c}\text { Subject could not imagine } \\
\text { the rotation of object } \\
\text { perfectly. }\end{array}$ & $\begin{array}{l}\text { Subject misunderstood with } \\
\text { the direction of object and he } \\
\text { could not draw the } \\
\text { appropriate object. }\end{array}$ & True & $\begin{array}{c}\text { Subject could not } \\
\text { determine the plane form. }\end{array}$ \\
\hline SF-1 & True & True & $\begin{array}{l}\text { Subject could not draw object } \\
\text { from the projection perfectly. }\end{array}$ & $\begin{array}{l}\text { Subject just estimated the } \\
\text { distance of two objects. }\end{array}$ & $\begin{array}{c}\text { Some answers were not } \\
\text { true as she did not estimate } \\
\text { well. }\end{array}$ \\
\hline SF-2 & True & $\begin{array}{l}\text { Subject could answer } 2 \text { part } \\
\text { correctly but the other one is } \\
\text { false. It is because She can } \\
\text { not represented the object. }\end{array}$ & $\begin{array}{l}\text { Subject misunderstood with } \\
\text { the direction of object. }\end{array}$ & $\begin{array}{l}\text { Subject just imagine the } \\
\text { calculation of the path. She } \\
\text { did not calculate appropriate } \\
\text { and she did not compare } \\
\text { with other path }\end{array}$ & $\begin{array}{l}\text { Some answers were not } \\
\text { true as she just imagine the } \\
\text { object and did not } \\
\text { calculate. Moreover she } \\
\text { could not analyze the } \\
\text { distance estimation. }\end{array}$ \\
\hline SF-3 & $\begin{array}{l}\text { Subject could draw } \\
\text { the net, but the line } \\
\text { at in every side was } \\
\text { capsize. }\end{array}$ & $\begin{array}{l}\text { Subject could not imagine } \\
\text { the rotation of object well. }\end{array}$ & True & True & $\begin{array}{l}\text { Subject could not } \\
\text { determine the plane form } \\
\text { as she could not imagine } \\
\text { the object well. }\end{array}$ \\
\hline
\end{tabular}

TABLE 1. THE RESUlt OF SPATIAL ABILITy TEST

\section{A. Imaginary Manipulation of the Solid.}

Imaginary manipulation of the solid is ability showed the phases of objective activity that consist of complex spatial transformation of the solid. This type was identifying how students understand about object's transformation, such as 3 dimension object change to be 2 dimension object, how was the web from a solid object. In this research, imaginary manipulation could be identified by how student could change the three-dimensional object to two-dimensional object. Also, how students could placed the right object appropriately.

At this task, most of students answered the question correctly. All of students could create the web of cube. It was because they got material about web at junior high school, so they knew it well. However, some of students could not draw the were 5 types of spatial ability with the details were $69,69 \%$ student with imaginary manipulation of the solid, 24,39\% students with representation of the projection, $65 \%$ students with reconstruction object, $60,6 \%$ students with objective cognitive map, and 46,06\% students with balance cognitive map. The students of this class were grouped based on final score of solid geometry become three groups with classification of geometry skill, they are high geometry skill group, middle geometry skill group, and low geometry skill group. There were 2 students, male and female, at each group. Subject SM-1 and SF-1 were high group, while subject SM-2 and SF-2 were middle group, and Subject SM-3 and SF-3 were low group. Table 1 showed the result of analyze of students spatial skill. 
connected. However, Subject SF-3 did not draw the correct line at left side of Picture 1. Subject SF-3 drew a line with false direction. If she drew like that, the lines was not connected from one side to other side at the cube. At interview section, Subject SF-3 was asked to change the net which she drawn to the cube. When she analyzed how the cube formed from the net, she just realized that the lines were not connected at the left side. The error was happen as Subject SF-3 just imagined how the cube was drown at the net side by side. It mean that Subject SF-3 imagined how could the cube changed become the net, then she imagined the line side by side. Thus, she drew the line one by one, and she did not check again whether the net was true or not by changing the net become cube again. In addition, other female subjects drew the correct answer, it was the net with appropriate line.

Based on Picture 2, male subject SM-3drew correct net with appropriate line at each side. However, he forgot to drew the point A. At interview section, Subject SM-3 said that he just forgot to drew it because he just focused on the net and line at each side. It could be said that Subject SM-3 did not draw the object carefully. Moreover, two other male subjects drew the net correctly with appropriate line at each side.

Based on the explanation, female subject with low abilities could not drew the net with appropriate line on each side, while other female subject could did it. On the other hand, all of male subject could draw two-dimensional object with line at each side correctly, although male subject with low abilities had careless to draw point A. Error in imaginary manipulation of the solid showed that subject did not have enough ability about imaging object whether from three-dimensional to two-dimensional object or from two-dimensional to three-dimensional.

\section{B. The Projection of Solid}

The second task is identifying how students understand about the projection of solid object, and also how a solid object could be seen as its projection. The task's purpose was producing and drawing the two-dimensional projection picture of a three-dimensional solid. The characterized of this task is analytical operations from concrete to abstract. This task tested students how a solid object and its representation could be seen by mobilizing the experience of the motion, changing inner viewpoint, imaginary rotation, manipulation of mental representations. Those are the answer of number two by Subject SF-3 and MF-3.

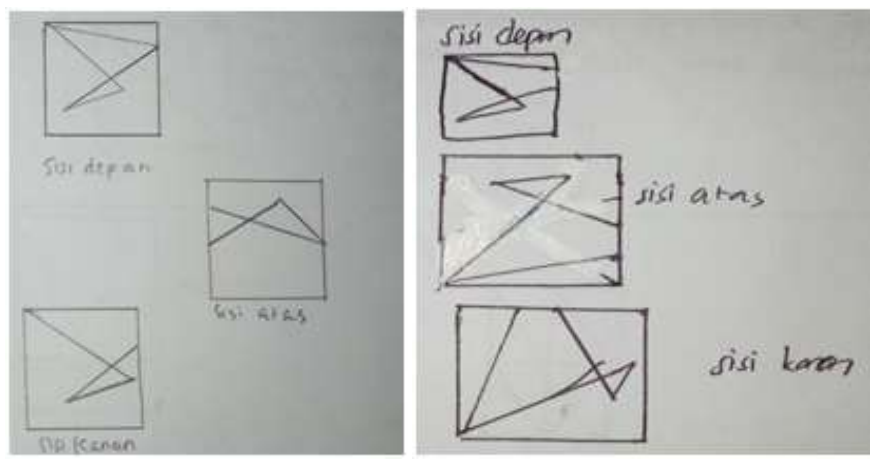

Fig 3. Answer of Subject SF-3 on number 2

Fig 4. Answer of Subject SM-3 on number 2
Based on Picture 3, Subject SF-3 could not draw correctly the object of the projection of three-dimensional object to twodimensional object. At solid object, the vertex were placed at the edge, then, from all side the vertex always placed at the edge. Besides, the line also was seen from all side. However, at front side, Subject SF-3 drew the vertex was not placed at the edge. It was similar with her picture from above side, while her picture from right side, she did not draw the line between two vertex. Subject SF-3 was predicted that she imagined only object that can be seen. Subject SF-3 could not imagine how the object form after it rotated whether the side in front or right side, or above side. At interview section, Subject SF-3 explained that she drew the what just she saw at the picture. Subject SF-3 had imagined how the object form if it rotated, but she could not imagine perfectly. Moreover, Subject SF-3 only drew what is the picture showed.

On the other hand, male subject SM-3 had the similar answer with Subject SF-3. Subject SM-3 could not draw correctly. Both at front side, right side, and above side, Subject SM-3 disconnected two lines at two-dimensional object. In contrast, the line at three-dimensional were connected each others. Thus, Subject SM-3 did not draw the projection correctly. At interview section, it happened as Subject SM-3 just seen the picture as real and he did not imagine the real object well.

Those are the answer of number two by Subject SF-2 and SM-2.

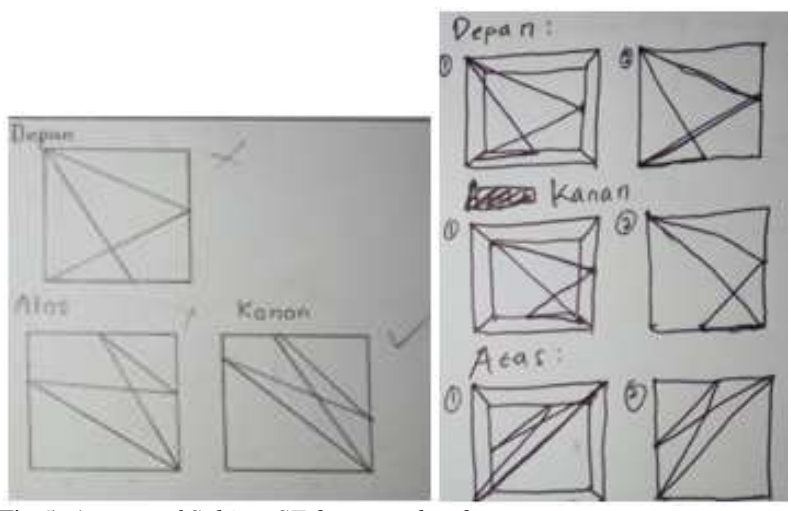

Fig 5. Answer of Subject SF-2 on number 2

Fig 6. Answer of Subject SM-2 on number 2

Based on picture 5, Subject SF-2 answered the questions correctly at projection of three-dimensional based on front side and right side, while the projection from above side, her answer was not true. At that projection, Subject SF-2 drew the wrong position. At interview section, it was found because Subject SF2 saw the object after it was rotated, so she just draw at that position. Meanwhile at picture 6, Subject SM-2 had the unique way to determine the projection of three dimensional solid object. Firstly, he draw the rotated object at three dimension form. After that he could see the object which was formed. Then, he just drew it at two dimension. 


\section{Reconstruction}

Reconstruction was ability about how students could make reconstruction solid object. This task is identifying how students could create a axonometrical picture of the solid based on the projection that have been given. At this reconstruction phase, students synthesize the visual information by studying and understanding the projection pictures. The axonometrical picture would be constructed by the series of changing the inner viewpoint and by harmonizing three channels.

At this task, most students did not answer correctly. It was because some of them did not understand what was the problems about and other students could understand what question of the problem but they could not draw appropriately. Those are the answer of number three by Subject SF-1 and SM1
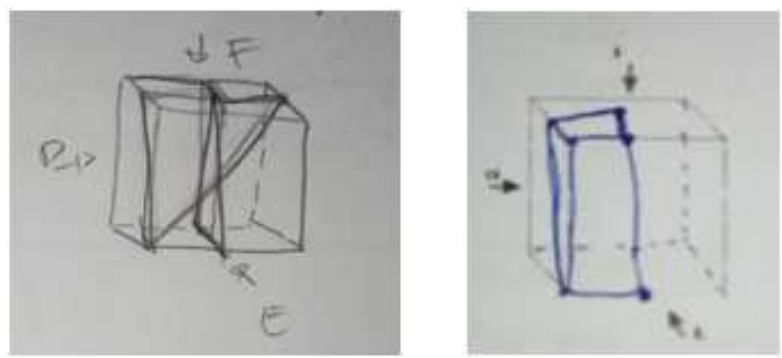

Fig 7. Answer of Subject SF-1 on number 3

Fig 8. Answer of Subject SM-1 on number 3

Based on picture 7, Subject SF-1 could not draw the solid object correctly. Subject SF-1 understood what was the problem and what the purpose of the problem. However, Subject SF-1 draw one by one the projection to the solid object, and she assumed that it was axonometrical picture like number one. Besides, she also draw the addition line based on her assumption. On the other hand, based on picture 8, Subject SM1 did not draw the object obviously. At interview section, Subject SM-1 guessed that side E was under part. Thus, Subject SM-1 drew the line disconnected each other.

\section{Objective Cognitive Map}

Objective cognitive map was an ability about predicted and analyzed the distance between two objects. The purpose This task was to identifying how students could analyze about distance include to determine the shortest path between two objects. Those are the answer of number four by Subject SF-2 and SM-2

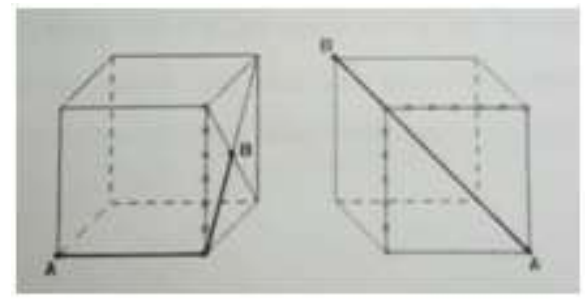

Fig 9. Answer of Subject SF-2 on number 4

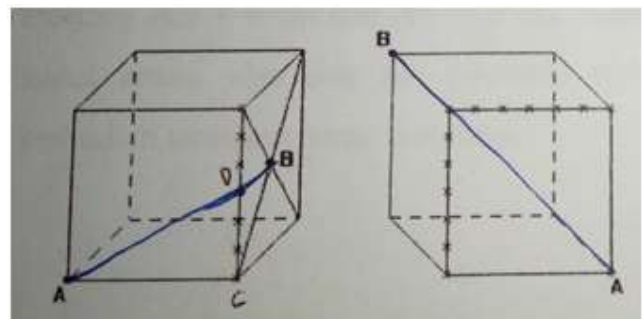

Fig 10. Answer of Subject SF-2 on number 4

Based on picture 9, Subject SF-2 draw the right answer at the right picture, while the left picture was false. Subject SF-2 determined the shortest path by predicted that the distance was shortest, but she did not calculate it and she did not compare it with others path. Meanwhile, based on picture 10, male subject SM-2 choose the right path to get the shortest distance. At interview, Subject SM-2 did not calculate it too, but he just compared with other path which was shorter.

\section{E. Balance Cognitive Map}

\section{CONCLUSION}

At mathematics students in colleague, there were 5 types of spatial ability which made by students. There were $69,69 \%$ student with imaginary manipulation of the solid, $24,39 \%$ students with representation of the projection, $65 \%$ students with reconstruction object, $60,6 \%$ students with objective cognitive map, and 46,06\% students with balance cognitive map. Thus, the dominant type which was mastered by majority mathematics students in colleague is imaginary manipulation of solid. It was about how students could change the solid three dimension object to become two dimension object. In Addition, the dominant error at spatial ability at mathematics students in colleague was representation of the projection. It was about how students could make and draw the appropriate projection from three dimension object to two dimension object. There were some causative factors that influenced why students made error. They were: (1) female students lack of ability to imagine the object, (2) students only seen at the pictures without imagine how the pictures in real, (3) students could not interpret and understand what the problems, and (4) students did not real calculate the distance of two objects, it mean they only predicted the distance, and also they did not compare with other path to determine the shortest distance.

\section{REFERENCES}

[1] A. Özerem Misconceptions in Geometry and Suggested Solutions For Seventh Grade Students in Procedia Social and Behavioral Sciences, SciVerse ScienceDirect 55, 720-729. 2012

[2] M.C. Linn, and A.C. Petersen, "Emergence and Characteization of Sex Differences in Spatial Ability: A Meta-Analysis," Society for Research in Child Development, Vol. 56, No. 6, pp 1479-1498, December 1985. 
[3] National Council of Teachers of Mathematics Curiculum and Evaluation Standards for School Mathematics (Reston V A: National Council of Teachers of Mathematics), 2000

[4] M.E.R.Purnomo, dan I.U. Machromah," Geometri Ruang di Perguruan Tinggi: Kesalahan Mahasiswa Menyelesaikan Soal Berdasarkan Prosedur Newmann," Prosiding Seminar Nasional Matematika dan Pendidikan Matematika UNY

[5] N. Riastuti, M. Mardiyana, and I Pramudya, " Students' Errors in Geometry Viewed from Spatial Intelligence,” International Conference on Mathematics and Science Education (ICMScE), Journal of Physics: Conf. Series 895 (2017) 012029.

[6] M. Applebaum,' Spatial Abilities as a predictor to Success in the Kangaroo Contest, Journal of MMathematics and System Science 7 (2017) 154-163.

[7] Maier, P. H. 1998. Spatial Geometry and Spatial Ability-How to Make Solid Geometry Solid? In Elmar Cohors-Fresenborg, K. Reiss, G. Toener, and H.-G. Weigand, editors, Selected Papers from The Annual Conference of Didactics of Mathematics 1996, Osnabrueck, p. 63-75. 